
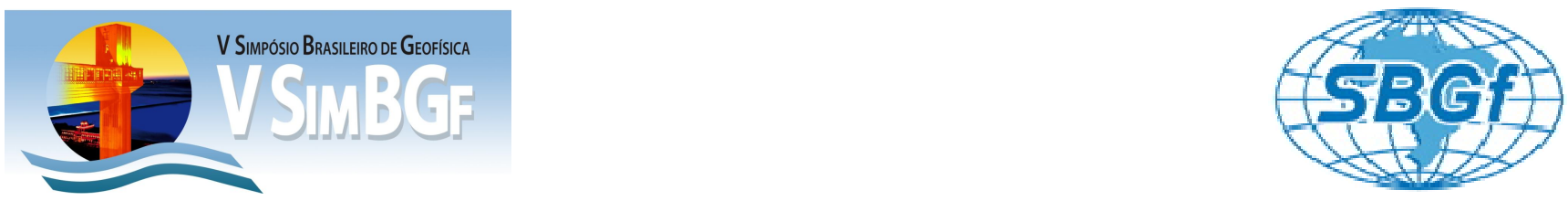

\title{
Monitoramento geotérmico raso em Balbina, Presidente Figueiredo-Amazonas
}

\author{
João da Silva Carvalho - DEGEO/UFAM (jscarvalho@ufam.edu.br) \\ Rutenio Luiz Castro de Araujo - DEGEO/UFAM (ruie@ufam.edu.br) \\ Cristiano de Abreu Silva - DEGEO/UFAM (kuri_182@yahoo.com.br) \\ Cisnea Menezes Basílio - DEGEO/UFAM (cisnea_geo@hotmail.com)
}

Copyright 2012, SBGf - Sociedade Brasileira de Geofísica

Este texto foi preparado para a apresentação no V Simpósio Brasileiro de Geofísica, Salvador, 27 a 29 de novembro de 2012. Seu conteúdo foi revisado pelo Comitê Técnico do V SimBGf, mas não necessariamente representa a opinião da SBGf ou de seus associados. É proibida a reprodução total ou parcial deste material para propósitos comerciais sem prévia autorização da SBGf.

\section{Resumo}

Um monitoramento geotérmico raso foi realizado em uma chácara localizada no Distrito de Balbina (Presidente Figueiredo/AM), onde ocorrem sedimentos arenosos da Formação Nhamundá (Grupo Trombetas), com o objetivo de avaliar os efeitos antrópicos no comportamento diurno da estrutura geotermal rasa. Esse levantamento foi realizado em duas etapas, envolvendo os períodos chuvoso (janeiro de 2010) e de estiagem (agosto de 2010), e constou de medidas horárias de temperatura superficial, a 0,5 e a 1,0 metro de profundidade, em dois locais contíguos, sendo um com cobertura vegetal e outro sem cobertura vegetal. Os resultados mostram pequenas variações térmicas entre os dois períodos investigados, assim como a grande estabilidade térmica a 1,0 metro de profundidade, onde as variações diurna e sazonal são inferior a $0,3^{\circ} \mathrm{C}$.

\section{Introdução}

Foi realizado um monitoramento geotérmico raso em uma chácara localizada no km 68 da rodovia AM-240, próximo à margem direita do rio Uatumã, Distrito de Balbina/Presidente Figueiredo-AM (Figura 1), onde ocorrem sedimentos eminentemente arenosos da Formação Nhamundá, unidade estratigráfica da porção inferior do Grupo Trombetas (Caputo et al., 1972; Cunha et al., 1994), constituido por alternâncias de depósitos marinhos e glaciogênicos, e constitui a Supersequência Ordovício-Devoniana da Bacia do Amazonas (Cunha et al., 2007). Localmente são expostos produtos de alteração intempérica dessas litologias, representado por solo arenoso, fino, esbranquiçado, onde sua porção superior apresenta coloração escura, relacionada à presença de matéria orgânica. O monitoramento em questão foi realizado em duas etapas, envolvendo os períodos chuvoso (janeiro de 2010) e de estiagem (agosto de 2010), e constou de medidas horárias de temperatura superficial, a 0,5 e a 1,0 metro de profundidade, em dois locais contíguos, sendo um com cobertura vegetal e outro sem cobertura vegetal.

O principal objetivo deste trabalho foi avaliar os efeitos da interferência de fatores antrópicos no comportamento diurno da estrutura geotermal rasa (até a profundidade de 1,0 metro), a partir da mensuração das variações térmicas diurnas e sazonais, tendo como escopo a avaliação ambiental e de conforto térmico.

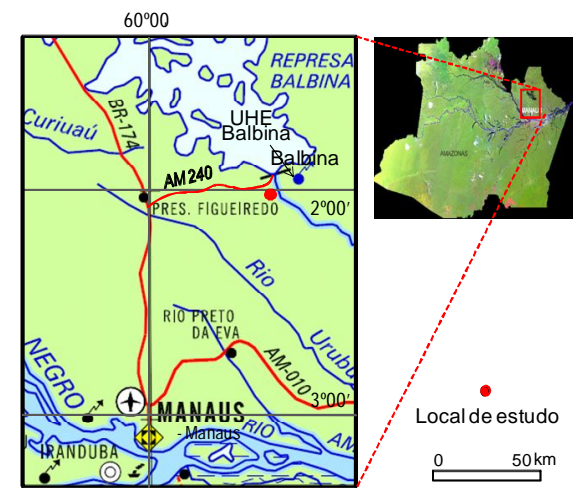

Figura 1 - Mapa dos locais de realização dos levantamentos geotérmicos

\section{Fundamentação teórica}

Empiricamente, admite-se que a temperatura no núcleo terrestre pode chegar a mais de $5.000^{\circ} \mathrm{C}$ (Wyllie, 1976; Khan, 1980; Teixeira et al., 2001; Press et al., 2006), ainda que, na superfície terrestre, a média é da ordem de $28^{\circ} \mathrm{C}$. Esse fato define a existência de um aumento sistemático da temperatura com a profundidade, e estabelece um gradiente de calor no sentido da superfície terrestre, cuja dissipação (fluxo geotermal), produz uma energia da ordem de $64 \mathrm{~mW} / \mathrm{m}^{2}$ por ano (Teixeira et al., 2001) e inclui todos os processos geotermais (calor residual, calor produzido por decaimento radioativo, reações químicas e processos tectônicos e magmáticos). A superfície terrestre recebe ainda um fluxo de radiação solar incidente, o qual gera uma perturbação térmica, que se propaga em direção às camadas subsuperficiais (Araujo, 1999), sendo esse fenômeno mais significativo na região equatorial terrestre, devido à maior inclinação dos raios incidentes. A dinâmica da propagação dessa perturbação térmica, para a subsuperfície, depende de vários fatores, que inclui as características da radiação incidente, questões climáticas, características térmicas das formações geológicas, natureza e grau de proteção superficial e fluxo de calor proveniente do interior da Terra, além da interferência humana (Molion, 1987, 1991). Portanto, essa camada superficial terrestre é palco de importantes processos de interação energética, com destaque para essas fontes térmicas principais e, o entendimento da atuação desses processos, é de grande importância econômica, social, humana e ambiental, 
porque dela dependemos para nossa própria sobrevivência.

As atividades antrópicas, na forma de ocupação e uso do solo para qualquer fim, que normalmente envolve a retirada da vegetação, promovem fortes desequilíbrios ambientais, cujas influências podem ter abrangência em escala local, regional ou mesmo global, a depender da amplitude do empreendimento. As consequências da investidura para fins de ocupação urbana, normalmente tornam-se significativamente mais danosas ao ambiente físico, devido às diferentes formas de agressão, a exemplo de ocupações de áreas inapropriadas, ampla impermeabilização da superfície, destruição do equilíbrio ambiental local, lançamento de agentes poluidores em todos os ambientes, forte assoreamento de drenagens, as quais promovem fortes perturbações no ambiente local e contribuem para o desequilíbrio ambiental regional e global. Um efeito dessas ações é o aumento da sensação de calor devido, principalmente, ao aumento da temperatura da superfície devido à absorção de calor.

\section{Métodos de trabalho}

O método de estudo consistiu de um monitoramento geotérmico em dois locais contíguos, distanciados de cerca de 20 metros, sendo um com cobertura vegetal (com arborização secundária, efetiva), que exerce uma proteção contra a incidência direta da radiação solar, e outro sem cobertura vegetal (gramínea rala), no qual a radiação solar incide direto sobre o solo. O levantamento de campo foi realizado em duas etapas, sendo a primeira no período de 08 a 11 de janeiro de 2010 (período chuvoso) e o segundo no início do período de estiagem (04 a 07 agosto de 2010), ambos durante um período de 72 horas, a partir de medidas obtidas em sensores (termístores) instalados sobre a superfície, e constou de medidas horárias de temperatura com sensores posicionados sobre a superfície terrestre $(0,0 \mathrm{~m})$, a $0,5 \mathrm{~m}$ e a 1,0m de profundidade.

As medidas de campo (resistência elétrica, dadas em $\mathrm{Ohm}$ ) foram convertidas para valores de temperatura $\left({ }^{\circ} \mathrm{C}\right)$ por meio de uma tabela de calibração. Com esses resultados foram construídos gráficos de valores de temperatura em função do tempo de realização dos monitoramentos, para cada situação ambiental (com e sem cobertura vegetal) e para cada profundidade de investigação $(0,0 \mathrm{~m}, 0,5 \mathrm{~m}$ e $1,0 \mathrm{~m})$, com base nos quais foram efetuadas as devidas análises, de acordo com procedimentos empregados por outros autores, entre os quais Araujo et al. (1995), Araujo et al. (1998), Araujo (1999), Araujo et al. (2001), Araujo et al. (2004), ; Silva et al. (2006) e Carvalho et al. (2010).

\section{Apresentação e discussão dos resultados}

O levantamento em questão foi realizado em duas etapas, sendo uma em janeiro de 2010 , representativo do período úmido (chuvoso) e outro em agosto de 2010, representativo do período de estiagem (período seco regional).

1. Monitoramento realizado em janeiro de 2010
O levantamento geotérmico realizado em janeiro de 2010 constou da obtenção de valores horários de temperatura $\left({ }^{\circ} \mathrm{C}\right)$, de forma concomitante para os locais com cobertura vegetal $(\mathrm{CCV})$ e sem cobertura vegetal (SCV), no período das 14:00h do dia 08.01.2010 às 14:00h do dia 11.01.2010.

Os resultados desse monitoramento, para o local com cobertura vegetal, estão mostrados na Figura 2, onde se observa que os valores de temperatura para a superfície (profundidade de 0,0m) oscilou entre um mínimo de $24,59^{\circ} \mathrm{C}$ a um máximo de $28,79^{\circ} \mathrm{C}$, com variação de $4,2^{\circ} \mathrm{C}$, e com média de $26,24^{\circ} \mathrm{C}$. Para a profundidade de $0,5 \mathrm{~m}$, a variação foi da ordem de $0,11^{\circ} \mathrm{C}$, com oscilação de $26,3^{\circ} \mathrm{C}$ a $26,41^{\circ} \mathrm{C}$ e com média de $26,35^{\circ} \mathrm{C}$. Para as leitura a $1,0 \mathrm{~m}$ de profundidade, as temperaturas ficaram, ao longo desse período, relativamente estáveis, com oscilação entre $26,61^{\circ} \mathrm{C}$ e $26,66^{\circ} \mathrm{C}$, tendo a variação da ordem de $0,05^{\circ} \mathrm{C}$ e média de $26,63^{\circ} \mathrm{C}$.

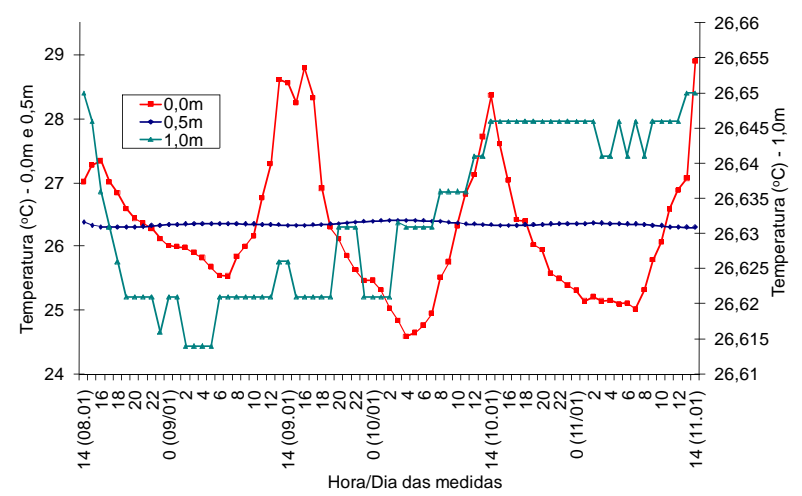

Figura 2 - Perfis do monitoramento geotérmico realizado em Balbina, no período de 08 a 11 de janeiro de 2010, para o local com cobertura vegetal (CCV).

As temperaturas a $1,0 \mathrm{~m}$ de profundidade estiveram, ao longo desse período, sempre superiores às observadas a $0,5 \mathrm{~m}$ de profundidade, configurando a existência de um fluxo ascendente entre esses dois níveis.

O pico máximo na superfície normalmente ocorreu por volta de 14:00 horas, enquanto que a $0,5 \mathrm{~m}$ de profundidade se verificou por volta de 01:00h/02:00h (ambos com comprimento de onda de 24 horas), determinando uma defasagem de cerca de 11 a 12 horas para a onda de calor que atinge a superfície chegar a $0,5 \mathrm{~m}$ de profundidade. Para 1,0 metro de profundidade um pico máximo de calor foi observado por volta das 14:00 horas do dia 11/Jan, concernente à onda de calor originada com defasagem temporal da ordem de 72 horas, em relação à superfície.

Para o local sem cobertura vegetal (Figura 3), os valores de temperatura superficiais variaram de $24,72^{\circ} \mathrm{C}$ a $40,72^{\circ} \mathrm{C}$ (oscilação de $16,0^{\circ} \mathrm{C}$ e média de $28,71^{\circ} \mathrm{C}$ ). Para $0,5 \mathrm{~m}$ de profundidade a variação observada foi de $0,5^{\circ} \mathrm{C}$, (oscilação de $28,17^{\circ} \mathrm{C}$ a $28,67^{\circ} \mathrm{C}$ e média de $28,40^{\circ} \mathrm{C}$ ). Para as leitura a $1,0 \mathrm{~m}$ de profundidade as temperaturas oscilaram de $28,67^{\circ} \mathrm{C}$ a $28,75^{\circ} \mathrm{C}$ (variação de $0,08^{\circ} \mathrm{C}$ e média de $28,69^{\circ} \mathrm{C}$ ). A defasagem de tempo entre os picos observados na superfície (14:00h) e 0,5m (02:00h do dia seguinte) foi da ordem de 12 horas. A 1,0 m, essa defasagem é estimada como da ordem de 72 horas. 
As temperaturas observadas a $1,0 \mathrm{~m}$ de profundidade mantiveram-se frequentemente superiores às observadas a $0,5 \mathrm{~m}$ de profundidade, configurando um fluxo ascendente entre esses dois níveis.

Para ambos os casos (locais CCV e SCV), existem períodos em que a temperatura superficial é maior que à 0,5m (normalmente entre 09:00h e 19:00h), quando se verifica um fluxo descendente (para a sbsuperfície).

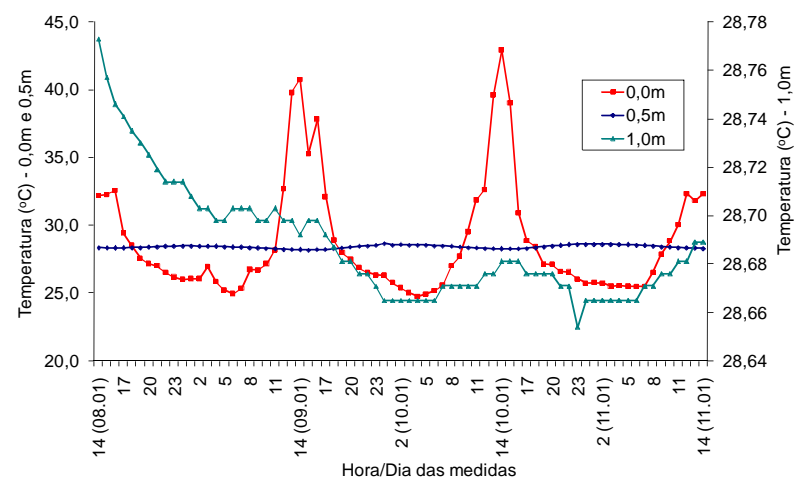

Figura 3 - Perfis do monitoramento geotérmico realizado em Balbina (PF/AM), no período de 08 a 11 de janeiro de 2010, para o local sem cobertura vegetal (SCV).

2. Monitoramento geotérmico realizado em agosto de 2010

Esse monitoramento geotérmico foi realizado no período das 12:00 horas de 04 ás 14:00 horas do dia 07.08.2010, totalizando 74 horas de monitoramento. As medidas foram obtidas nos mesmos locais e com os mesmo procedimentos do levantamento anterior.

Conforme pode ser observado na Figura 4, para o local com cobertura vegetal (CCV), os valores de temperatura superficial oscilaram entre $24,2^{\circ} \mathrm{C}$ a $29,5^{\circ} \mathrm{C}$ (variação da ordem de $5,3^{\circ} \mathrm{C}$ e média de $25,99^{\circ} \mathrm{C}$ ), a $0,5 \mathrm{~m}$ oscilaram entre $25,95^{\circ} \mathrm{C}$ a $26,14^{\circ} \mathrm{C}$ (variação da ordem de $0,19^{\circ} \mathrm{C}$ e média de $26,04^{\circ} \mathrm{C}$ ) e a $1,0 \mathrm{~m}$ de profundidade oscilaram entre $26,214^{\circ} \mathrm{C}$ a $26,243^{\circ} \mathrm{C}$ (variação da ordem de $0,03^{\circ} \mathrm{C}$ e média de $26,233^{\circ} \mathrm{C}$ ).

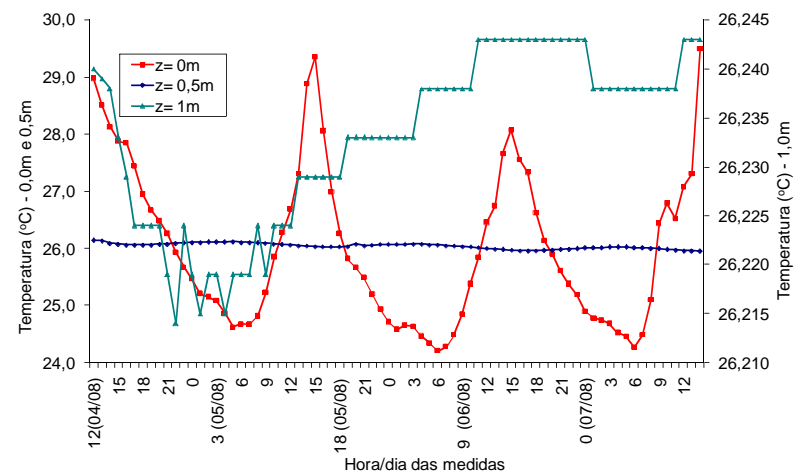

Figura 4 - Perfis do monitoramento geotérmico realizado em Balbina, no período de 04 a 07 de agosto de 2010, para o local com cobertura vegetal (CCV).

Semelhante ao levantamento anterior, as temperaturas observadas a 1,0 metro de profundidade mantiveram-se constantemente superiores àquelas a 0,5 metro, significativo de fluxo de calor ascendente nesse intervalo. Os picos máximos de temperatura observados na superfície ocorreram por volta das 14:00 horas, alcançando a profundidade de $0,5 \mathrm{~m}$ por volta $06: 00$ horas do dia seguinte, portanto com uma defasagem de 16 horas, Foi observado um pico mínimo a 1,0 metro de profundidade, ocorrido por volta das 02:00 horas do dia 04/Ago, que dever estar relacionado a uma defasagem da ordem de 72 horas.

Para o local sem cobertura vegetal (Figura 5) os valores de temperatura superficiais oscilaram entre $25,47^{\circ} \mathrm{C}$ a $36,25^{\circ} \mathrm{C}$ (variação da ordem de $10,78^{\circ} \mathrm{C}$ e média de $28,62^{\circ} \mathrm{C}$ ), de $29,58^{\circ} \mathrm{C}$ a $30,12^{\circ} \mathrm{C}$ (variação da ordem de $0,54^{\circ} \mathrm{C}$ e média de $29,85^{\circ} \mathrm{C}$ ) nas medidas a $0,5 \mathrm{~m}$ e de $29,38^{\circ} \mathrm{C}$ a $29,45^{\circ} \mathrm{C}$ (variação da ordem de $0,07^{\circ} \mathrm{C}$ e média de $29,42^{\circ} \mathrm{C}$ ) nas medidas a $1,0 \mathrm{~m}$ de profundidade.

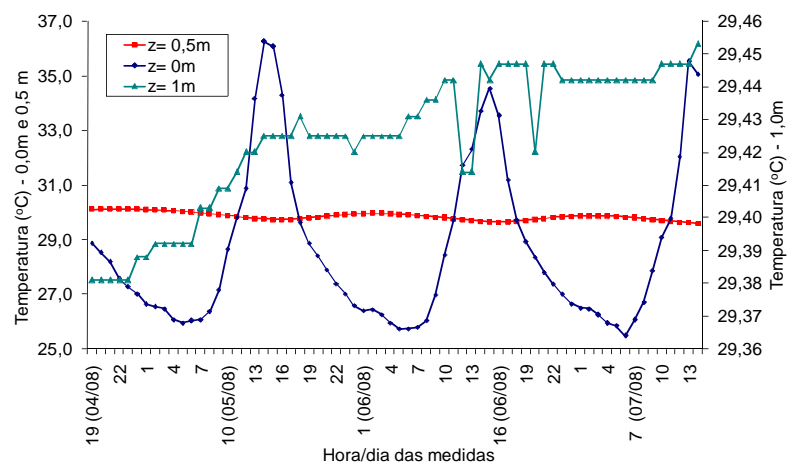

Figura 5 - Perfis do monitoramento geotérmico realizado em Balbina (PF/AM), no período de 04 a 07 de agosto de 2010, para o local sem cobertura vegetal (SCV).

Conforme observado na Figura 5, os valores de temperatura a $0,5 \mathrm{~m}$ de profundidade estiveram, ao longo do período, frequentemente superiores às medidas a $1,0 \mathrm{~m}$ de profundidade, o que caracteriza um fluxo de calor descendente. Também nesse caso, os picos máximos de temperatura observados na superfície ocorreram por volta das 14:00 horas, alcançando a profundidade de 0,5m por volta 06:00 horas do dia seguinte, com uma defasagem de 16 horas. A 1,0 metro de profundidade não foi possível observar, com clareza, a chegada dessa onda de calor, para o intervalo de tempo investigado, embora se possa estimar, com base nos dados disponíveis, como sendo da ordem de 72:00 horas.

Do mesmo modo como verificado no levantamento anterior, também se observa momentos, ao longo desse período, em que ocorre mudança no sentido de fluxo entre a superfície $(0,0 \mathrm{~m})$ e 0,5 metro de profundidade (figuras 4 e 5), que acontece normalmente entre 10:00 e 19:00 horas, correspondente à maior insolação.

Para esse local, comparando os resultados observados nos monitoramentos realizado em janeiro/2010 (período chuvoso) e agosto/2010 (período de estiagem), verificase que, para o local com proteção de vegetação (Figura $6)$, as temperaturas superficiais no período chuvoso (jan/2010), em grande parte foram superiores às temperaturas (nos mesmos horários) em ago/2010. As diferenças médias observadas entre os dois 
levantamentos foi de $0,442^{\circ} \mathrm{C}$ (com máxima diferença inferior a $1,0^{\circ} \mathrm{C}$ ).

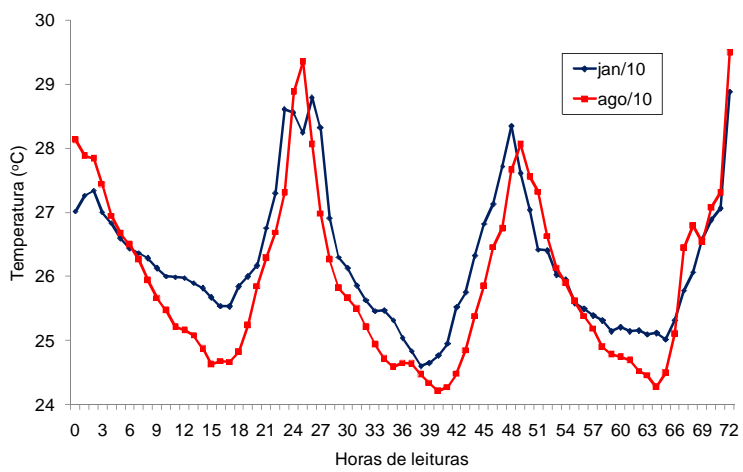

Figura 6 - Perfis comparativos de temperatura superficial (0,0m) para o local CCV, em Jan/2010 e Ago/2010

Para o local sem cobertura vegetal (SCV) verifica-se uma inversão de comportamento (em relação ao local com proteção vegetal), sendo, onde os valores de temperatura superficiais no período de estiagem (ag/2010) apresentaram-se, em grande parte, superiores às temperaturas (nos mesmos horários) em jan/2010 (Figura 7).

As diferenças médias observadas entre os dois levantamentos foi de $0,442^{\circ} \mathrm{C}$, onde a diferença máxima chegou a mais de $8,0^{\circ} \mathrm{C}$.

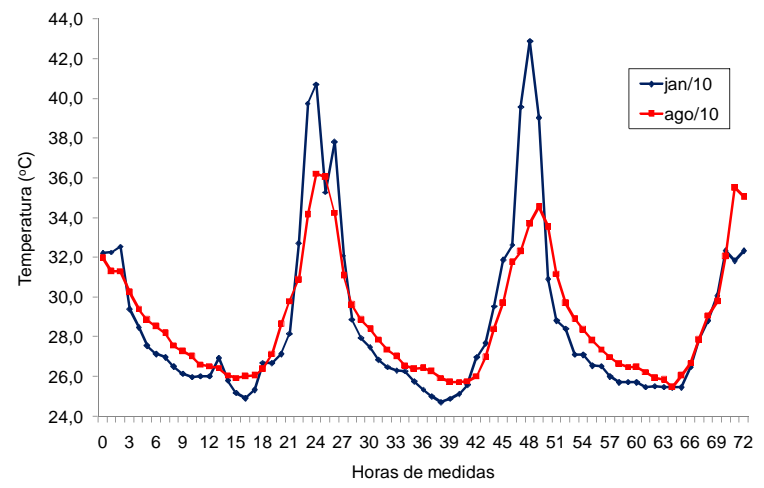

Figura 7 - Perfis comparativos de temperatura superficial (0,0m) para o local SCV, em Jan/2010 e Ago/2010

De um modo geral, as temperaturas superficiais obtidas no monitoramento realizado no período de jan/2010, são frequentemente maiores no local SCV, comparado ao local SCV. Em termos médios, essa diferença de temperatura superficial foi da ordem de $3,46^{\circ} \mathrm{C}$ (maior no local SCV), sendo que, puntualmente, apresentou diferença de até $13,5^{\circ} \mathrm{C}$ (Figura 8).

No monitoramento realizado em ago/2010 é nítida a supremacia sistemática dos valores de temperatura superficial entre os locais com cobertura vegetal (CCV) e sem cobertura vegetal (SCV), ainda que, em média, a diferença é de apenas $2,85^{\circ} \mathrm{C}$, e puntualmente essa diferença não chega a $7,0^{\circ} \mathrm{C}$.(Figura 9).

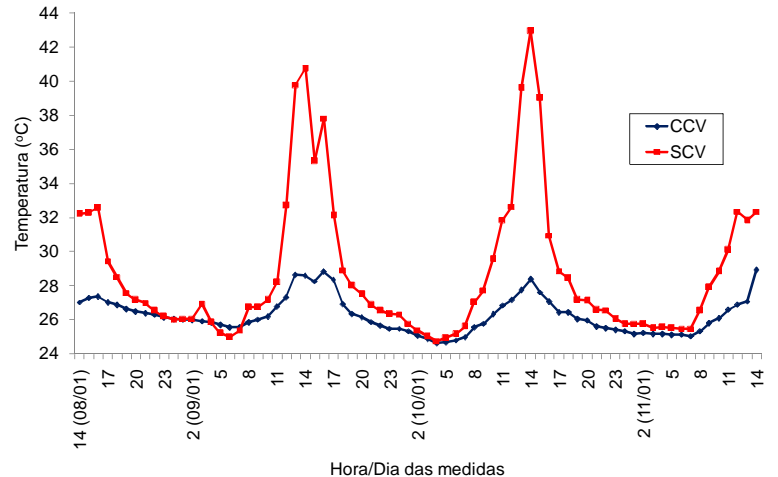

Figura 8 - Perfis comparativos de temperatura superficial $(0,0 \mathrm{~m})$ para os locais CCV e SCV, em Jan/2010

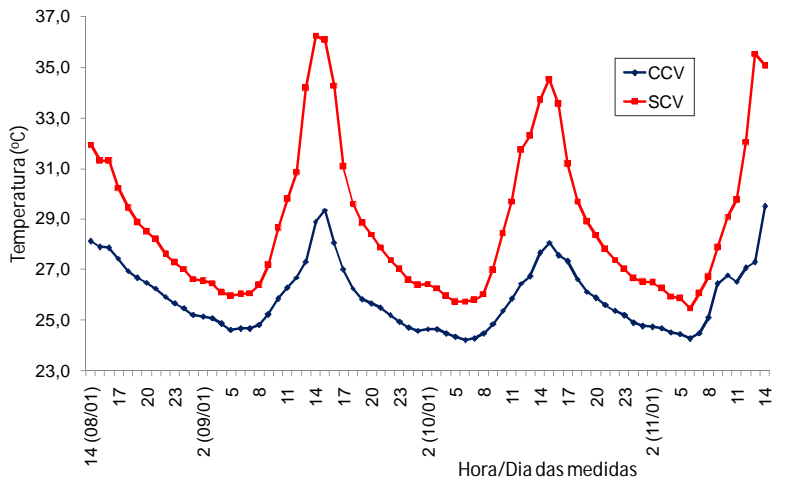

Figura 9 - Perfis comparativos de temperatura superficial $(0,0 \mathrm{~m})$ para os locais CCV e SCV, em Ago/2010

\section{Conclusões}

Os resultados das medidas de monitoramento de temperatura nos locais com e sem proteção da vegetação, em dois períodos representativos das estações úmida e seca regional, quer na superfície como nas profundidades de 0,5 e 1,0 metro, permitiram observar o comportamento da estrutura geotermal diurna e sazonal, nesse local.

Para o monitoramento realizado no local sem cobertura vegetal e no período de estiagem (ago/2010), verificou-se um fluxo de calor descendente (da profundidade de $0,5 \mathrm{~m}$ para $1,0 \mathrm{~m}$ ), o que caracteriza um maior fornecimento de calor a partir da superfície, devido ao período de maior insolação. Por lado, para monitoramento realizado em jan/2010 (período chuvoso) e no local com cobertura vegetal do período de estiagem, verificou-se um fluxo de calor ascendente da profundidade de $1,0 \mathrm{~m}$ para $0,5 \mathrm{~m}$. Isso caracteriza uma acumulação anterior de energia térmica a $1,0 \mathrm{~m}$ de profundidade, que faz dissipar esse calor no sentido da superfície. Esse fato revela, também, a importância da vegetação como atenuadora do impacto da insolação sobre a superfície terrestre, além de causar um maior equilíbrio na temperatura nas profundidades rasas $(0,5 \mathrm{~m}$ e 1,0m, nesse caso). Esse fato tem uma importância muito grande na questão do conforto térmico, e deve ser considerado por ocasião dono planejamento 
de ocupação do solo, quer para habitação como para a agricultura e piscicultura.

Os valores de temperatura superficiais mais elevados em jan/2010 que em ago/2010, mostra uma anomalia ocasional, uma vez que era esperado comportamento inverso, devido às características desses dois períodos. Da mesma forma, o comportamento mais regular quando comparadas as temperaturas superficiais nos locais com e sem cobertura vegetal, também é reflexo desse comportamento ambiental anômalo.

Para a determinação da defasagem temporal de chegada da onda de calor resultante da insolação diurna até à profundidade de $1,0 \mathrm{~m}$ deve-se ao período (72 horas) do monitoramento, que mostrou ser insuficiente, havendo a necessidade de ser mais prolongado.

\section{Agradecimentos}

Agradecemos à Fundação de Amparo à Pesquisa do Estado do Amazonas (FAPEAM), pelo apoio financeiro à realização deste trabalho, à Universidade Federal do Amazonas pelo disponibilização da estrutura laboratorial (incluindo instrumentação) necessária para a realização das atividades de campo, ao Sr, Walfran Lima, pela permissão de permanência no local de estudo, durante a realização dos trabalhos de campo, à minha esposa Dulcimar Silveira, pela companhia e apoio durante as atividades de campo.

\section{Referências}

Araujo, R.L.C. 1999. Contribuição da Geotermia Rasa aos Estudos Ambientais. EDUA ed., Manaus (AM), 86p.

Araujo, R.L.C.; Monteiro, I.B. \& Carvalho, J.S. 2001. Influência do conteúdo de água sobre os valores de condutividade térmica. Anais do VIII Simpósio de Geologia da Amazônia. Belém (PA), outubro, 3p.

Araujo, R.L.C.; Carvalho, J. S. \& Souza, J.R.S. 1995. A influência da umidade sobre os valores de condutividade térmica da subsuperfície. Revista Brasileira de Geofísica. 13(2): 111-118.

Araujo, R.L.C.; Makino, M.; Souza, J.R.S. \& Carvalho, J.S. 1998. Variações do fluxo geotermal raso. Anais do VI Simpósio de Geologia da Amazônia, Belém, Maio, 103105.
Araujo, R.L.C.; Silva, R. M.; Carvalho, J.S. \& Monteiro, I. B. 2004. Influência ambiental sobre a estrutura geotermal rasa. Revista Brasileira de Geofísica, RBGf, Rio de Janeiro, 22(1):33-44.

Caputo, M. V; Rodrigues, R. \& Vasconcelos, D. N. N. 1972. Nomenclatura Estratigráfica da Bacia do Rio Amazonas. In: Congr. Bras. Geol., 26. SBG. Belém, V.3, p.35-46.

Carvalho, J.S.; Araujo, R.L.C.; Abreu, C. S. \& Basílio, C. M. 2010. Monitoramento geotérmico raso em Presidente Figueiredo (AM). In: Anais do 45ํㅡㄹ Congresso Brasileiro de Geologia, SBG, Curitiba (PR). Versão digital (CD).

Cunha, P. R. C; Gonzaga, F. G; Coutinho, L. F. C. \&; Feijó, F. J. 1994. Bacia do Amazonas. In: Bol. de Geoc., PETROBRÁS, Rio de Janeiro (RJ), 8(1): 47-55.

Cunha, P.R.C.; Melo, J.H.G. \& Silva, O.B. 2007. Bacia do Amazonas. Boletim de Geociências da Petrobrás, 15(2.): 227-251.

Khan, M. A. 1980. Geologia Global, Paraninfo, Madrid, $216 p$.

Molion, L. C. B. 1987. Micrometeorology of Amazonian Rainforest. In: Geophysiology of Amazonian, R. E. Dickinson (Ed): John Wiley and Songs, UNU, 255-270.

Molion, L. C. B. 1991. Climate Variability and its Effects on Amazonian Hidrology. In: Water Management of Amaz0nian Basin, UNESCO/ABRH, Braga, B. \& Fernandez, p.261-274.

Press, F., Siever, R., Grotzinger \& Jordan. 2006 Para entender a Terra. Bookman, Porto Alegre, 656p.

Silva, R. M.; Araujo, R.L.C.; Carvalho, J.S. \& Monteiro, I. B. 2006. Influência da cobertura vegetal na estrutura térmica da subsuperfície. Dê Ciência . Revista de Publicação Científica da Uninorte. Uninorte, Rio Branco (AC), 1(1):107-123.

Teixeira, W.; Toledo, M. C. M.; Fairchild, T. R. \& Taioli, F. 2001. Decifrando a Terra. Oficina de Textos, São Paulo, $568 p$.

Wyllie, P. J. 1976. A Terra - Nova Geologia Global, Fundação Calouste Gulbenkian, Lisboa, 384p. 